решения 3D-Micromac для лазерного отжига, используемого в техпроцессе при производстве OLED- и LED-дисплеев. В экспозиции 3D-Micromac были представлены системы roll-to-roll micro FLEX для лазерной обработки гибких компонентов. Приложения этих систем можно найти в структурировании гибких солнечных элементов, производстве датчиков для медицинских и электронных приложений, в производстве гибких дисплеев.

Бельгийская компания Newson специализируется на выпуске модульных лазерных систем, работающих при отклонениях от положения равновесия. Они применяются в системах с движущейся оптикой, в которых необходимо стабильное положение лазерного луча, направленного в рабочую точку зоны обработки.

Заметно, что компании-производители лазеров и лазерных установок сами в своей экспозиции предлагают технические решения, которые могут быть встроены в конкретные индустриальные процессы. Например, Coherent и поглощенный им ROFIN представили широкую линейку лазеров с различными длинами волн и выходной мощностью, но при этом компании дополнили свою экспозицию демонстрацией интеграционных решений - "систем под ключ". То есть производители лазерных источников и систем не ждут, пока посетитель догадается, как использовать лазер, а сами адаптируют свой продукт к конкретному применению, выступая уже в роли интегратора.

TRUMPF проводит политику - "от источника луча к датчикам", показывая, как интеграция продуктов компании может встроиться в любой, от резки до маркировки, производственный процесс. На выставке были предложены готовые решения: системы объединяют множество компонентов - от лазеров до сенсорных датчиков. TRUMPF провозглашает: "У клиентов нашей компании не возникнет необходимости покупать лазер у одного поставщика, а оптику - у другого". Традиционные для TRUMPF продукты - $\mathrm{CO}_{2}$-лазеры с длиной волны 10,6 мкм, несмотря на всеобщее увлечение волоконными лазерами, по-прежнему актуальны. Они имеют явное преимущество в случае резки крупнотолщинных материалов. Кроме того, $\mathrm{CO}_{2}$-лазеры используются для получения экстремального ультрафиолетового излучения (ЭУФ-излучения) с длиной волны 50-60 нм, которое востребовано литографическим оборудованием. Для контроля сварного шва используют датчики, принцип работы которых основан на методе оптической когерентной томографии. Он позволяет реконструировать 3D-изображение шва в ходе лазерной сварки для оптимизации процесса в режиме реального времени.

Швейцарская компания Synova продемонстрировала свою машину гибрида лазерной и гидроабразивной резки.

Frankfurt Laser Company традиционно представила диодные системы всевозможных модификаций разной мощности и длины волны излучения. С учетом интереса, проявляемого клиентами к индустриальным приложениям, компания Frankfurt Laser Company включила в портфель предлагаемых продуктов высокомощные диодные лазерные системы с оптоволоконным выходом и оптической мощностью до 3000 Вт. Эти системы могут работать как CW-режиме, так и модулироваться с частотами модуляции до 20 кГц.

Компания OXАРA представила различные стекла и материалы для их обработки самого широкого спектра.

Лазерные технологии укрепляют свои позиции в области обработки поверхностей различных форм и разных материалов, маркировки и аддитивных технологий 3D-печати. Понятно, что в массовом производстве дисплеев и скрайбировании фотовольтаических панелей, в промышленной лазерной микрообработке и глубокой гравировке без сканаторных головок не обойтись.
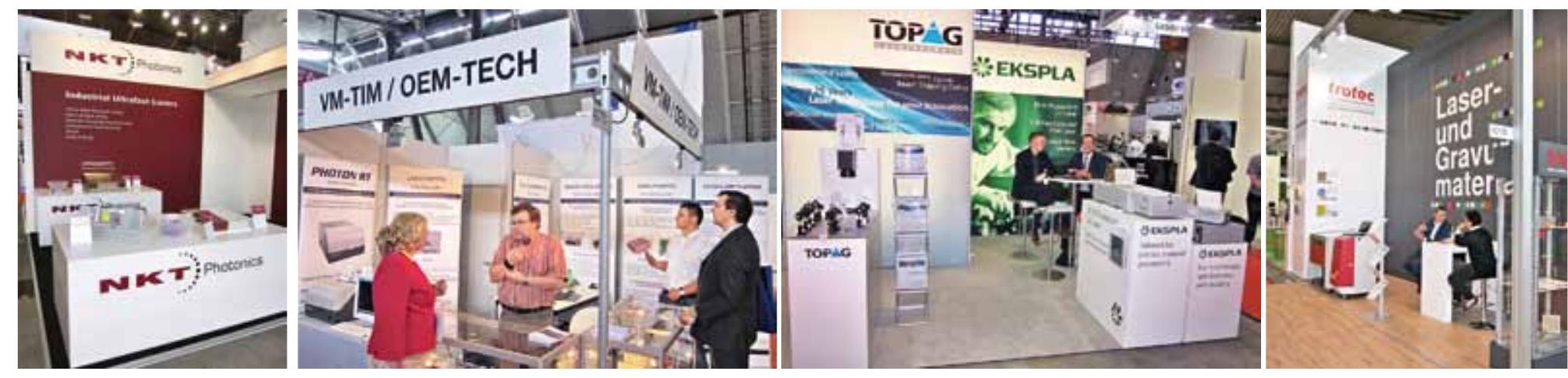
Компании SCANLAB, учитывая высокий спрос на высокоточные сканирующие системы, анонсировала систему сканирования для массового производства. Сканирующая головка excellisCAN разработана для эксплуатации в самых жестких условиях лазерной обработки на длинах волн 1064 , 532 и 355 нм, максимальная мощность, выдерживаемая зеркалами, 250 Вт. За счет использования новых сервоприводов достигается более высокая динамика без ущерба точности, таким образом значительно повышается производительность процесса. Скорость позиционирования < $30 \mathrm{M} / \mathrm{c}$, рекомендуемый момент инерции $1,2 \Gamma^{\circ} \mathrm{CM}^{2}$.

Спектр применений лазерных источников постоянно растет. Так в связи с расширением использования компонентов из углепластика (CFRP) для создания облегченных конструкций (в автомобилестроении и авиации) увеличился выпуск лазеров с ультракороткими импульсами (УКИ). СFRР-компоненты очень дороги из-за способа их изготовления, и часто при возникновении дефектов встает вопрос не о замене компонентов из углепластика, а об их ремонте. Для удаления поврежденных участков используются УКИлазеры, для склеивания элементов используют также импульсные лазеры с другой шириной импульса. УКИ-лазеры пользуются преимуще ством для очистки поверхностей. Преимущество лазерной очистки в том, что материал изделий не повреждается химически, механически или термически. Лазерная очистка пресс-форм и инструментов от лака, резины, силикона, сажи, вулканизованных остатков, ржавчины, масла и жира позволяет бережно обработать поверхности.

Отметим большой интерес, который вызвала у посетителей продукция мирового лидера в производстве волоконных лазеров компании IPG Photonics - семейство лазерных инструментов для медицины. Приборы реализуют режимы с излучением на оптимальных длинах волн, с энергетическими и импульсными характеристиками, востребованными самыми разными медицинскими специалистами. Если на прошлых выставках компания демонстрировала достижения волоконными лазерами высоких мощностей излучения, то теперь линейка продуктов расширилась за счет УКИ-лазеров с выверенными режимами от 300 фемтосекунд до 10 пикосекунд с энергией в импульсе от 5 до 100 милиджоулей. Компания IPG Photonics представила и мощные волоконные УКИ-лазеры для резки материалов, и УКИ-лазеры для микроэлектронной индустрии, в том числе для маркировки пластиков.

Отметим, что по сравнению с прошлой выставкой 2016 года на выставке LASYS-2018 увеличилось число компаний-участников, представляющих оборудование для вытяжки дыма и фильтрации воздуха. Функции новых систем расширились по сравнению с возможностями ранее выпускаемых машин для вытяжки. Современные системы очистки и дымоудаления предназначены не только для извлечения, фильтрации и очистки от дыма и частиц, образовавшихся в процессе обработки материалов, но и снабжены системами контроля за параметрами их рабочего состояния. Кроме того системы возвращают на рабочее место чистый воздух. В этой области прочные позиции занимают компании BOFA, ULT и ТВН. Причина роста числа компаний, выпускающих системы очистки, кроется в развитии рынка лазерных систем на основе УКИ-лазеров и их внедрении в индустрию товаров массового спроса. Так, даже датская компания NKT Photonics, которая известна своими замечательными волоконнооптическими датчиками, на выставку привезла УКИ-лазеры для индустриальных применений. А для склейки волокон, в том числе и специальных структурированных волокон, компания Fujikura изготавливает портативные аппараты. Такая продукция по-прежнему пользуется повышенным спросом, несмотря на нестабильность промышленного рынка.
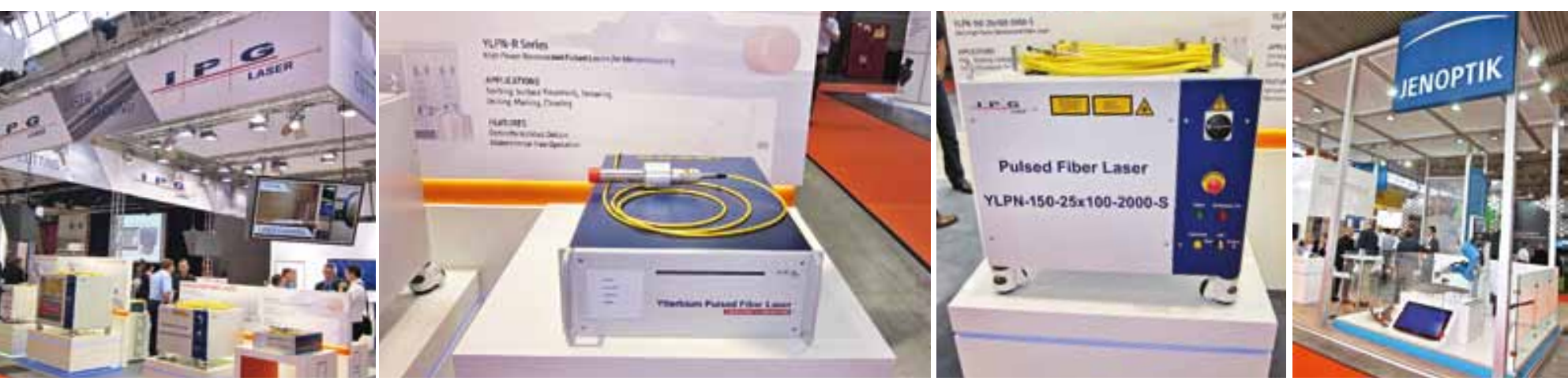


\section{9 달}

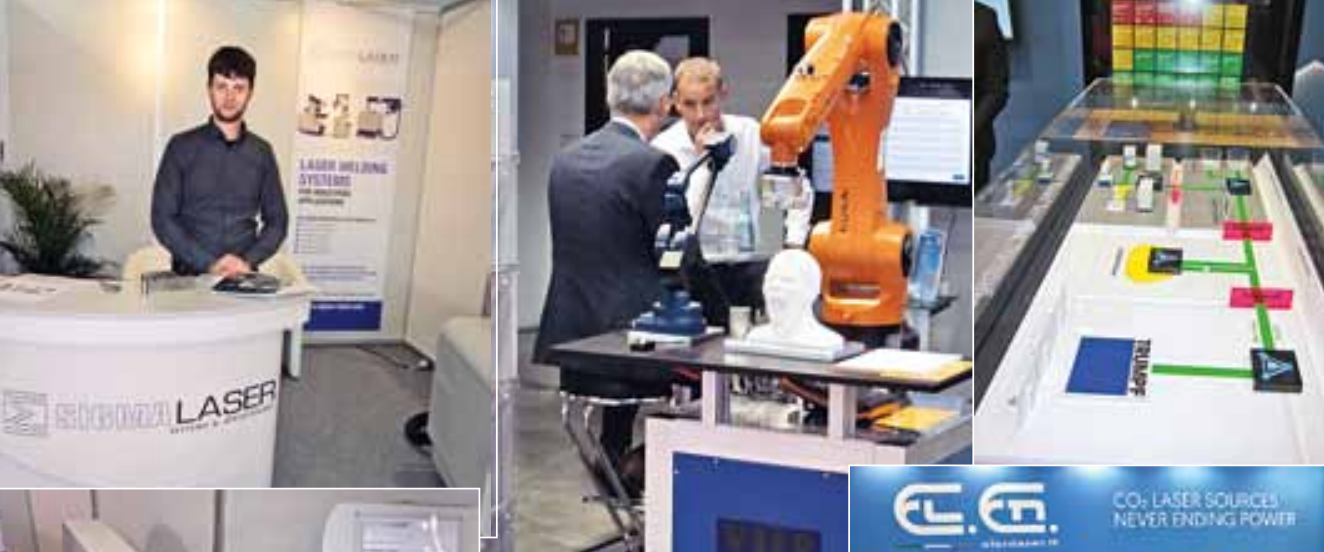

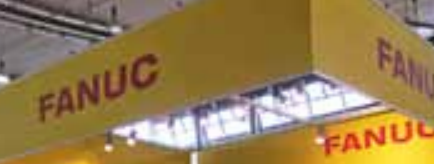

(c) 1

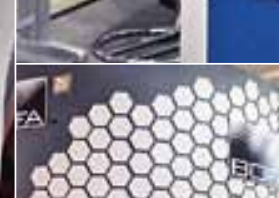

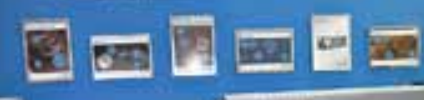

ars:

in

anta

Honth

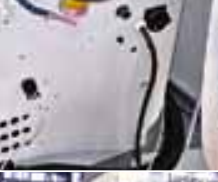

$\triangle 5$

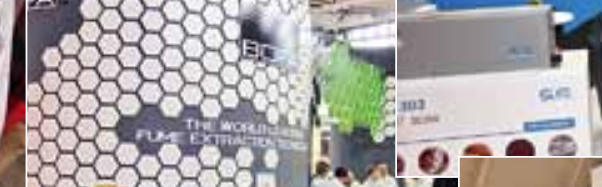

100000

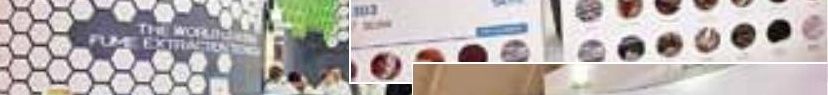
\%EKSPLA

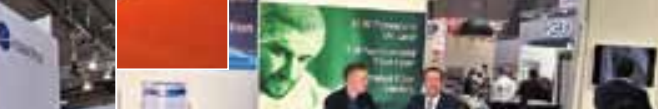
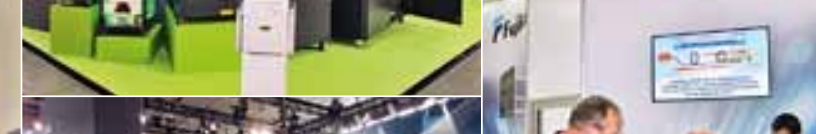

$\square$ and की $x^{2}=7.4$

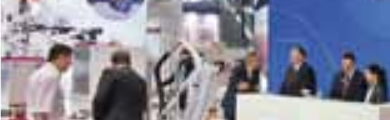
7920

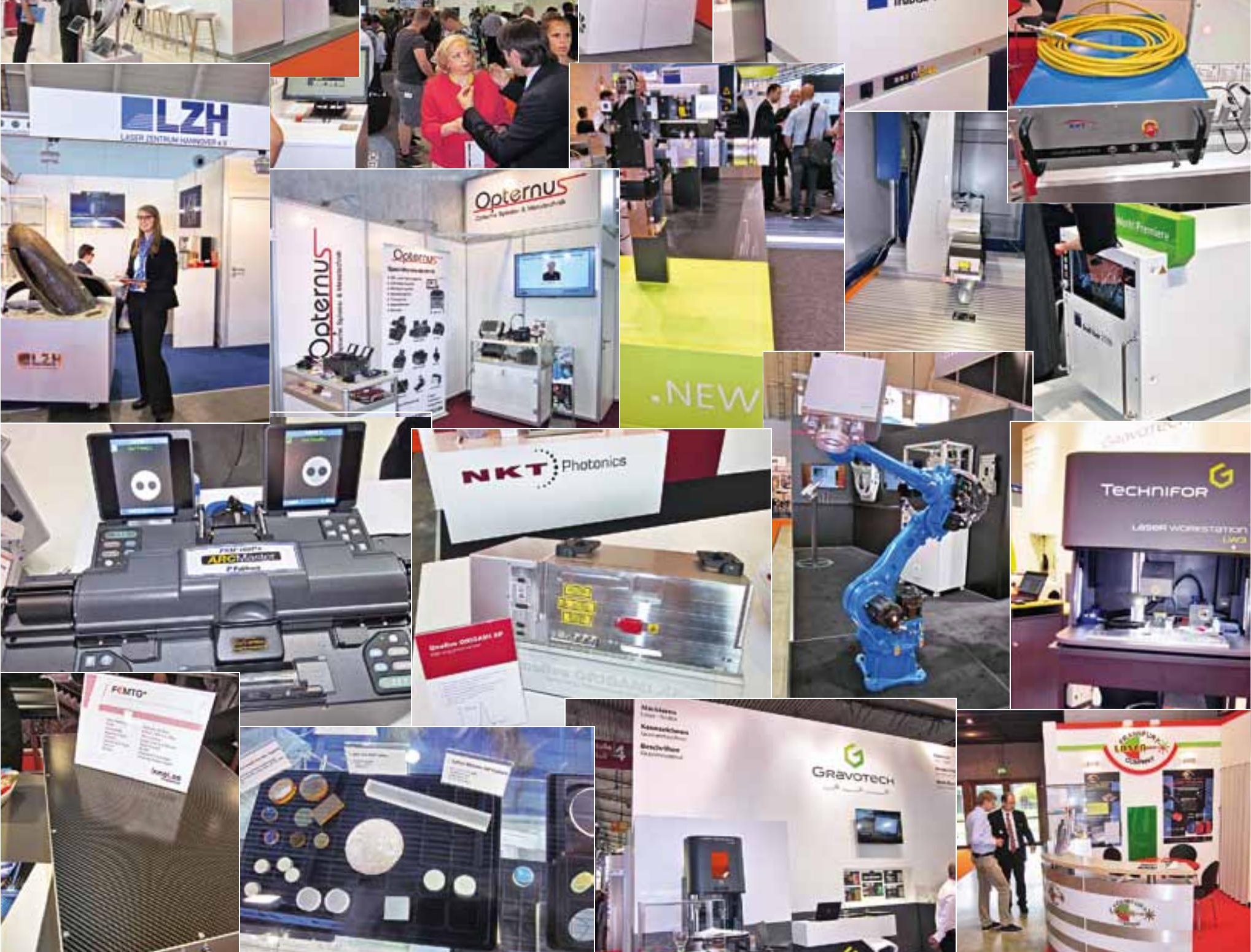

